\title{
Telmisartan, an angiotensin-II receptor blocker ameliorates cardiac remodeling in rats with dilated cardiomyopathy
}

\author{
Vijayakumar Sukumaran ${ }^{1}$, Kenichi Watanabe ${ }^{1}$, Punniyakoti T Veeraveedu ${ }^{1,2}$, Rajarajan A Thandavarayan ${ }^{1}$, \\ Narasimman Gurusamy ${ }^{3}$, Meilei $\mathrm{Ma}^{1}$, Ken’ichi Yamaguchi ${ }^{4}$, Kenji Suzuki ${ }^{5}$, Makoto Kodama ${ }^{6}$ \\ and Yoshifusa Aizawa ${ }^{6}$
}

Multiple trials over the past several years have examined indications for angiotensin receptor blockers (ARBs) in the treatment of left ventricular (LV) dysfunction, both acutely after myocardial infarction and in chronic heart failure (CHF). However, the effects of telmisartan, an ARB in rats with CHF after experimental autoimmune myocarditis (EAM) have not yet been analyzed. CHF was elicited in Lewis rats by immunization with cardiac myosin, and 28 days after immunization, the surviving Lewis rats were divided into two groups and treated with either telmisartan $\left(10 \mathrm{mg} \mathrm{kg}^{-1}\right.$ day $\left.^{-1}\right)$ or vehicle. After 4 weeks of treatment, we analyzed the effects of telmisartan on cardiac function, proinflammatory cytokines and cardiac remodeling in EAM rats. Myocardial functional parameters measured by hemodynamic and echocardiographic studies were significantly improved by telmisartan treatment in rats with CHF compared with those of vehicle-treated rats with CHF. Telmisartan significantly reduced levels of cardiac fibrosis, hypertrophy and its marker molecules (LV mRNA expressions of transforming growth factor beta 1, collagen I and III, and atrial natriuretic peptide), and peroxisome proliferator-activated receptor- $\gamma$ protein expression compared with those of vehicle-treated rats. CHF-induced increases in myocardial mRNA expressions of proinflammatory cytokines, (interleukin (IL)-6, IL-1ß), monocyte chemoattractant protein-1 and matrix metalloproteinases (MMP-2 and -9) were also suppressed by the treatment with telmisartan. Moreover, the plasma level of angiotensin-II was significantly elevated in telmisartan-treated rats. Our results indicate that telmisartan treatment significantly improved LV function and ameliorated the progression of cardiac remodeling in rats with CHF after EAM.

Hypertension Research (2010) 33, 695-702; doi:10.1038/hr.2010.67; published online 10 June 2010

Keywords: chronic heart failure; cytokine; myocardial fibrosis; PPAR- $\gamma$

\section{INTRODUCTION}

Dilated cardiomyopathy (DCM) is a set of heterogeneous diseases of left ventricular (LV) dysfunction because of unknown etiology. ${ }^{1}$ DCM is considered to follow myocarditis, ${ }^{2}$ and two mechanisms by which myocarditis develops into DCM have been suggested: one is persistent viral infection and the other is progressive autoimmune myocardial injury. ${ }^{3}$

A growing body of evidence shows that angiotensin II (Ang-II) type 1 receptor $\left(\mathrm{AT}_{1} \mathrm{R}\right)$-blockers $(\mathrm{ARB})$ inhibit cardiac hypertrophy and remodeling, and prevent progression of systolic heart failure, thereby reducing cardiac morbidity and mortality ${ }^{4}$ and reducing myocardial damage during myocarditis. ${ }^{5}$ The transition from compensated to failing cardiac hypertrophy has been attributed to a reversal to fetal pattern cardiomyocyte gene expression and results in ventricular remodeling. ${ }^{6}$ Many kinds of cytokines, such as basic fibroblast growth factor, Ang-II, transforming growth factor beta 1 (TGF- $\beta 1$ ), and collagen III, have been suggested to have an important role in structural remodeling of the nonmyocyte compartment of the myocardium after heart failure. ${ }^{7}$

Recent reports indicate that some $\mathrm{AT}_{1} \mathrm{R}$ antagonists inhibit nitric oxide production in macrophages ${ }^{8}$ and interleukin (IL)- $1 \beta$ production. ${ }^{9}$ Moreover, olmesartan, an $\mathrm{AT}_{1} \mathrm{R}$ antagonist, is shown to ameliorate experimental autoimmune myocarditis (EAM) by suppression of inflammatory events in the myocardium in addition to hemodynamic modifications. ${ }^{10}$

Both angiotensin converting enzyme inhibitors and $\mathrm{AT}_{1} \mathrm{R}$ antagonists have been used to treat a variety of cardiovascular diseases,

\footnotetext{
${ }^{1}$ Department of Clinical Pharmacology, Faculty of Pharmaceutical Sciences, Niigata University of Pharmacy and Applied Life Sciences, Niigata, Japan; ${ }^{2}$ Department of Biomedical Optics, WPI Immunology Frontier Research Center, Osaka University, Osaka, Japan; ${ }^{3}$ Department of Anesthesiology and Medicine, Brigham and Women's Hospital, Harvard Medical School, Boston, MA, USA; ${ }^{4}$ Department of Homeostatic Regulation and Development, Niigata University Graduate School of Medical and Dental Sciences, Niigata, Japan; ${ }^{5}$ Department of Gastroenterology and Hepatology, Niigata University Graduate School of Medical and Dental Sciences, Niigata, Japan and ${ }^{6}$ First Department of Medicine, Niigata University Graduate School of Medical and Dental Sciences, Niigata, Japan

Correspondence: Professor K Watanabe, Department of Clinical Pharmacology, Faculty of Pharmaceutical Sciences, Niigata University of Pharmacy and Applied Life Sciences, 265-1 Higashizima, Niigata city 956-8603, Japan.

E-mail: watanabe@nupals.ac.jp
}

Received 28 November 2009; revised 19 February 2010; accepted 22 February 2010; published online 10 June 2010 
including hypertension and cardiomyopathy. We have previously reported that candesartan treatment reduced mortality, heart weight (HW), myocardial fibrosis and mRNA expressions of TGF- $\beta 1$, and improved the survival rate and cardiac function in rats with DCM after myocarditis in a dose-dependent manner. ${ }^{11}$ So far, only a few studies have investigated the effects of $\mathrm{AT}_{1} \mathrm{R}$ blockade in experimental myocarditis. ${ }^{12}$ It is therefore important to determine the effect of ARBs on fetal gene expression or extracellular matrix (ECM) remodeling in models not only with heart failure after myocardial infarction, but also with DCM.

To date, the effects of telmisartan, an ARB, in the rat model of myosin-induced chronic heart failure (CHF) are unknown. Cardiac myosin-induced EAM is characterized by extensive myocardial necrosis, congestive heart failure and the appearance of multinucleated giant cells reflecting human giant cell myocarditis. Giant cell myocarditis is a fatal disorder, often leading to heart failure or arrhythmias. ${ }^{13}$ EAM was shown to progress into the clinicopathological state similar to DCM in the chronic phase, and was characterized by the enlargement of the heart, dilatation of ventricles, diffuse and extensive myocardial fibrosis, and hypertrophic and atrophic changes of myocardial fibers, resembling human cardiomyopathy. ${ }^{14}$ Thus, we plan to analyze the effects of telmisartan on cardiac function, proinflammatory cytokines and cardiac remodeling in a rat model of CHF after EAM.

\section{METHODS}

\section{Materials}

Telmisartan was generously provided by Boehringer Ingelheim GmbH (Ingelheim am Rhein, Germany), and Lewis rats (male, 8 weeks old) were purchased from Charles River Japan, Kanagawa, Japan.

\section{Experimental design}

All experiments were carried out using 8-week-old male Lewis rats and were performed in accordance with the guidelines of our institute. ${ }^{15}$ Lewis rats were injected in the footpads with antigen-adjuvant emulsion in accordance with a procedure described previously. ${ }^{15}$ In brief, porcine cardiac myosin was dissolved in phosphate-buffered saline at $5 \mathrm{mg} \mathrm{m}^{-1}$ and emulsified with an equal volume of complete Freund's adjuvant with $11 \mathrm{mg} \mathrm{ml}^{-1}$ Mycobacterium tuberculosis H37RA (Difco Lab, Detroit, MI, USA). CHF in rats was induced by immunization with $0.1 \mathrm{ml}$ of emulsion once by subcutaneous injection into the rear footpads ( $0.1 \mathrm{ml}$ to each footpad). The morbidity of EAM was $100 \%$ in rats immunized by this procedure..$^{15}$ Twenty-eight days after immunization, the surviving Lewis rats were divided into two groups and orally administered with telmisartan $\left(10 \mathrm{mg} \mathrm{kg}^{-1} \mathrm{day}^{-1}\right)$ or vehicle for 28 days. Age-matched Lewis rats without immunization were used as normal controls. It has been reported that telmisartan possesses an antifibrotic effect in hypertensive rats. ${ }^{16}$ As fibrosis has an important role in LV remodeling in our model, we chose the antifibrotic dose of telmisartan $\left(10 \mathrm{mg} \mathrm{kg}^{-1}\right)$ used in this previous study. ${ }^{16}$

\section{Hemodynamic and echocardiographic studies}

To obtain hemodynamic data, rats were anesthetized with $2 \%$ halothane in oxygen during the surgical procedures. A catheter-tip transducer (Miller SPR 249; Miller Instruments, Houston, TX, USA) was introduced into the left ventricle through the right carotid artery for the determination of peak LV pressure and LV end-diastolic pressure, and the rates of intraventricular pressure rise $(+\mathrm{d} P / \mathrm{d} t)$ and decline $(-\mathrm{d} P / \mathrm{d} t)$ were recorded as described previously. ${ }^{15}$ After instrumentation, the concentration of halothane was reduced to $0.5 \%$ to minimize the effects of anesthesia on hemodynamic parameters. Echocardiographic studies were carried out with a $7.5-\mathrm{MHz}$ transducer (Aloka, Tokyo, Japan). The LV dimensions in diastole and systole and percentage fractional shortening (FS) were estimated using M-mode measurements.

\section{Histopathology}

The body weight (BW) of rats was noted just before the surgical procedure. After the hemodynamic and echocardiographic analyses, the rats were killed, and the myocardium was isolated and weighed to calculate the ratio of HW to BW. The excised myocardium was kept in formalin and the midventricle sections were then embedded with paraffin. The paraffinized midventricle sections stained with Azan-Mallory dye and a color image analyzer (CIA-102; Olympus, Tokyo, Japan) were used to quantify the area of myocardial fibrosis (blue fibrotic area opposed to red myocardium). The results are presented as the ratio of the fibrotic area to the area of whole myocardium.

Using hematoxylin and eosin sections, myocyte diameter measurements were performed in 10 myocytes selected per field at 400 -fold magnification by light microscopy. Short-axis diameters of each myocyte were measured from the hearts of all groups of rats. Each average value was obtained on the basis of data from 10 myocytes and was used as an independent sampling data. In addition, inflammatory cell infiltration was identified using hematoxylin and eosin-stained sections in 100-fold magnification by light microscopy.

\section{Estimation of Ang-II by radioimmunoassay}

Blood samples were collected by heart puncture immediately after echocardiographic measurements, and were transferred into a chilled glass tube containing $0.25 \mathrm{ml}$ of $125 \mathrm{~mm}$ ethylene-diaminetetraacetic acid and $25 \mathrm{~mm}$ o-phenanthroline for the purpose of subsequent determinations of plasma Ang-II by standardized radioimmunoassay. ${ }^{17}$

\section{Immunohistochemistry}

Formalin-fixed, paraffin-embedded cardiac tissue sections were used for immunohistochemical staining. After deparaffinization and hydration, the slides were washed in Tris-buffered saline $\left(10 \mathrm{mml}^{-1}\right.$ Tris $\mathrm{HCl}, 0.85 \% \mathrm{NaCl}$, $\mathrm{pH}$ 7.5) containing $0.1 \%$ bovine serum albumin. Endogenous peroxidase activity was quenched by incubating the slides in methanol and $0.6 \% \mathrm{H}_{2} \mathrm{O}_{2}$ in methanol. To perform antigen retrieval, the sections were pretreated with trypsin for $15 \mathrm{~min}$ at $37^{\circ} \mathrm{C}$. After overnight incubation with the primary antibody, namely rabbit polyclonal anti-peroxisome proliferator-activated receptor- (PPAR- $\gamma$ ) antibody (diluted 1:100) (Santa Cruz Biotechnology, Santa Cruz, CA, USA), at $4{ }^{\circ} \mathrm{C}$, the slides were washed in Tris-buffered saline and horseradish peroxidase-conjugated secondary antibody was then added and the slides were further incubated at room temperature for $45 \mathrm{~min}$. The slides were washed in Tris-buffered saline and incubated with diaminobenzidine tetrahydrochloride as the substrate, and counterstained with hematoxylin. PPAR- $\gamma$-positive-stained cells of heart tissue were quantified in six selected fields per section at 400 -fold magnification by light microscopy, and the average of the total number of positive-stained cells of the six fields was recorded as the number of PPAR- $\gamma$-positive cells in the lesions.

\section{Western immunoblotting}

The myocardial tissue samples obtained from different groups were homogenized with lysis buffer. Protein concentrations in these homogenized samples were measured by the bicinchoninic acid method. For western blots, proteins were separated by sodium dodecyl sulfate-polyacrylamide gel electrophoresis and identified with the following antibodies to quantify the myocardial levels of proteins: rabbit polyclonal anti-PPAR- $\gamma$ antibody (diluted 1:100) and goat polyclonal anti-glyceraldehyde-3-phosphate dehydrogenase antibody (Santa Cruz Biotechnology). We used 10\% sodium dodecyl sulfate-polyacrylamide gel electrophoresis (Bio-Rad, Hercules, CA, USA), and electrophoretical transfer to nitrocellulose membranes. Membranes were blocked with $1 \%$ nonfat dry milk and $1 \%$ bovine serum albumin (Sigma, St Louis, MO, USA) in Trisbuffered saline- $\mathrm{T}$ (20 $\mathrm{mml}^{-1}$ Tris, $\mathrm{pH} 7.6,137 \mathrm{mml}^{-1} \mathrm{NaCl}$, and 0.05\% Tween). After incubation with primary antibody, the bound antibody was visualized with respective horseradish peroxidase-coupled secondary antibody (Santa Cruz Biotechnology) and chemiluminescence developing agents (Amersham Biosciences, Buckinghamshire, UK). The level of glyceraldehyde-3-phosphate dehydrogenase was estimated in every sample. Films were scanned, and band densities were quantified with densitometric analysis using Scion Image program (Epson GT-X700, Tokyo, Japan). Finally, western blot data were normalized with cardiac glyceraldehyde-3-phosphate dehydrogenase. 


\section{RNA extraction}

Heart tissues were preserved by immersion in RNAlater (Ambion, Austin, TX, USA) immediately after sampling. The extraction of total RNA was performed after homogenization by using Ultra TurraxT8 (IKA Labortechnik, Staufen, Germany) in TRIzol reagent (Invitrogen Corporation, Carlsbad, CA, USA) in accordance with the standard protocol. Synthesis of cDNA was performed by reverse transcription using total RNA $(2 \mu \mathrm{g})$ as a template (Super Script II; Invitrogen Corporation).

\section{Gene expression analysis by real-time RT-PCR}

Gene expression analysis was performed by real-time reverse transcription polymerase chain reaction (RT-PCR) (Smart Cycler; Cepheid, Sunnyvale, CA, USA) using CDNA synthesized from the CHF specimens. Real-time RT-PCR by monitoring with TaqMan probe (TaqMan Gene expression assays; Applied Biosystems, Foster City, CA, USA) was performed in accordance with the following protocol: $600 \mathrm{~s}$ at $95^{\circ} \mathrm{C}$, followed by thermal cycles of $15 \mathrm{~s}$ at $95^{\circ} \mathrm{C}$, and $60 \mathrm{~s}$ at $60^{\circ} \mathrm{C}$ for extension. Relative standard curves representing several 10 fold dilutions (1:10:100:1000:10 000:100 000) of cDNA from CHF tissue samples were used for linear regression analysis of other samples. Results were normalized to glyceraldehyde-3-phosphate dehydrogenase mRNA as an internal control and are thus shown as relative mRNA levels.

\section{Statistical analysis}

All values are expressed as means \pm s.e. Statistical analysis of differences between the groups was performed by one-way analysis of variance, followed by Tukey's or Bonferroni's and two-tailed $t$-test when appropriate. A value of $P<0.05$ was considered as statistically significant.

\section{RESULTS}

\section{Survival rate}

The effects of telmisartan on survival rate are shown in Figure 1 and Table 1. In all, $4(40 \%)$ and $1(10 \%)$ of the 10 rats in groups $V$ and T10, respectively, died between days 28 and 56 (Figure 1a and Table 1).
None of the rats in group $\mathrm{N}$ died. The survival rates were significantly higher in group T10 compared with those in group V $(P<0.01)$.

\section{Effects of telmisartan on myocardial functions}

Although heart rate was not different among the three groups of rats, central venous pressure and LV end-diastolic pressure were significantly higher and mean blood pressure, $\mathrm{LV}$ pressure and $\pm \mathrm{d} P / \mathrm{d} t$ were significantly lower in group $\mathrm{V}$ than in group $\mathrm{N}$, indicating systolic and diastolic dysfunction in vehicle-treated rats (Table 1). Central venous pressure and LV end-diastolic pressure were significantly decreased in the treatment T10 group compared with those in group V. Myocardial contractility parameters $\pm \mathrm{d} P / \mathrm{d} t$ were also improved in CHF rats treated with telmisartan. However, mean blood pressure and LV pressure were slightly improved by the treatment. Echocardiographic studies in group $\mathrm{V}$ rats showed evidence of LV remodeling, with increased LV dimensions in diastole and LV dimensions in systole $(P<0.01)$ and reduced FS and ejection fraction $(P<0.01)$, indicating impaired systolic function compared with that in group $\mathrm{N}$ rats (Table 1). Treatment with telmisartan significantly decreased LV dimensions in systole and increased FS and ejection fraction compared with those in group $\mathrm{V}$ (Table 1).

\section{Estimation of Ang-II}

The plasma Ang-II concentrations were significantly elevated in group $\mathrm{V}$ in comparison with those in group $\mathrm{N}$ (Figure $1 \mathrm{~b}$ ). Treatment with telmisartan significantly increased the plasma concentrations of Ang-II in comparison with those in group V (Figure 1b).

\section{Histopathology}

HW and HW/BW were significantly larger in group $\mathrm{V}$ than in group $\mathrm{N}$ rats (Table 1). Telmisartan significantly reduced $\mathrm{HW}$ and HW/BW

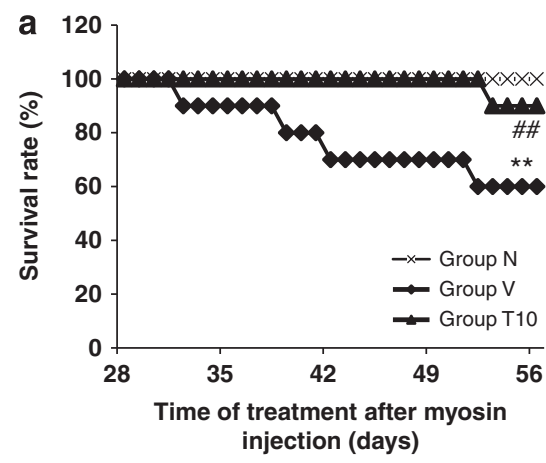

C

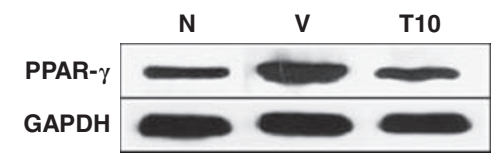

\section{b}
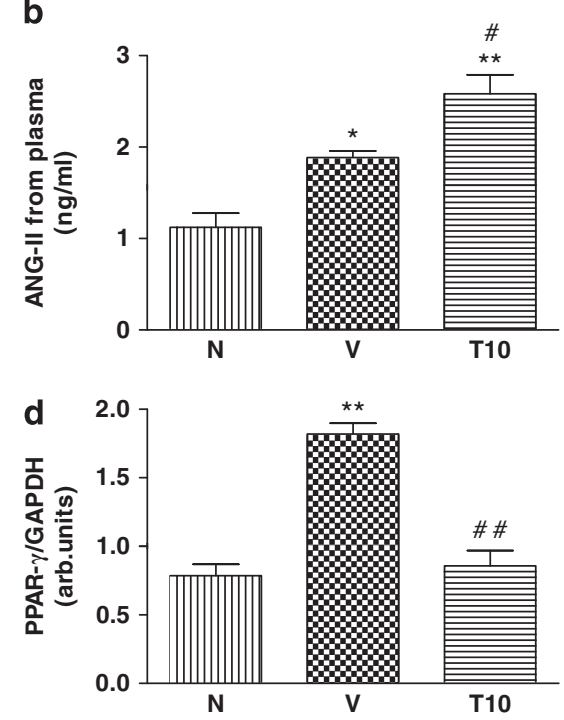

Figure 1 (a) The effects of telmisartan on survival rate in rats with CHF induced by autoimmune myocarditis. In all, 4 (40\%) and 1 (10\%) of 10 rats in groups $\mathrm{V}$ and $\mathrm{T} 10$, respectively, died between days 28 and 56 . None of the rats died in the normal group. The survival rates were significantly higher in group $\mathrm{N}$ than in group V. (b) Effects of telmisartan on neurohumoral parameter: plasma Ang-Il concentration. (c) Myocardial expressions of PPAR- $\gamma$ : Representative western blots showing specific bands for PPAR- $\gamma$ and glyceraldehyde-3-phosphate dehydrogenase (GAPDH) as an internal control. Equal amounts of protein sample obtained from whole ventricular homogenate were applied in each lane. (d) Densitometric data of protein analysis. The mean density value of PPAR- $\gamma$ was expressed as a ratio relative to that of GAPDH. Group N, age-matched untreated rats; group V, CHF rats administered with vehicle; group T10, CHF rats treated with telmisartan $\left(10 \mathrm{mg} \mathrm{kg}^{-1}\right.$ day $\left.{ }^{-1}\right)$. The values are mean \pm s.e.m. ${ }^{*} P<0.05$ and ${ }^{* *} P<0.01$ vs. group $\mathrm{N}$; ${ }^{\#} P<0.05$ and $\# \#<0.01$ vs. group V. 
Table 1 Changes in survival rate, hemodynamic, echocardiographic and histopathological parameters after 4 weeks of treatment with telmisartan in rats with CHF after EAM

\begin{tabular}{|c|c|c|c|}
\hline & $\begin{array}{l}\text { Group N } \\
(\mathrm{n}=10)\end{array}$ & $\begin{array}{l}\text { Group V } \\
(\mathrm{n}=10)\end{array}$ & $\begin{array}{c}\text { Group T10 } \\
(\mathrm{n}=10)\end{array}$ \\
\hline Survival rate (\%) & 100 & $60 * *$ & $90^{\# \#}$ \\
\hline BW (g) & $348 \pm 6.9$ & $310 \pm 6.0^{* *}$ & $259 \pm 10^{* *}$ \\
\hline HW (g) & $1.09 \pm 0.07$ & $1.52 \pm 0.29 * *$ & $0.90 \pm 0.04^{\# \#}$ \\
\hline HW/BW (g kg-1) & $2.64 \pm 0.22$ & $4.5 \pm 0.54^{* *}$ & $3.1 \pm 0.10^{\# \#}$ \\
\hline Area of fibrosis (\%) & $2.25 \pm 0.3$ & $33.8 \pm 1.3^{* *}$ & $15 \pm 2.0$ *\#\# \\
\hline CVP $(\mathrm{mm} \mathrm{Hg})$ & $0.09 \pm 0.4$ & $3.74 \pm 0.26^{* *}$ & $1.74 \pm 0.22^{* * \# \#}$ \\
\hline $\mathrm{MBP}(\mathrm{mm} \mathrm{Hg})$ & $98 \pm 2.8$ & $74 \pm 6.5^{*}$ & $82 \pm 5.8^{* *}$ \\
\hline LVP (mm Hg) & $114 \pm 6.0$ & $69 \pm 4.0^{* *}$ & $80 \pm 2.5^{* * \#}$ \\
\hline LVEDP (mm Hg) & $4.4 \pm 0.2$ & $11.2 \pm 0.8^{* *}$ & $5.6 \pm 0.4^{\# \#}$ \\
\hline$+\mathrm{d} P / \mathrm{d} t\left(\mathrm{~mm} \mathrm{Hg} \mathrm{s}^{-1}\right)$ & $5757 \pm 262$ & $3705 \pm 310 * *$ & $4421 \pm 332$ \\
\hline$-\mathrm{d} P / \mathrm{d} t\left(\mathrm{~mm} \mathrm{Hg} \mathrm{s}^{-1}\right)$ & $5683 \pm 316$ & $3788 \pm 164^{* *}$ & $4260 \pm 208^{\# \#}$ \\
\hline HR (beats min $^{-1}$ ) & $347 \pm 17$ & $317 \pm 14$ & $346 \pm 11$ \\
\hline LVDd (mm) & $6.2 \pm 0.64$ & $8.7 \pm 0.48^{*}$ & $7.5 \pm 0.30$ \\
\hline LVDs (mm) & $3.4 \pm 0.3$ & $7.2 \pm 0.59 * *$ & $5.4 \pm 0.3^{*}$ \\
\hline FS (\%) & $50 \pm 3.1$ & $14.4 \pm 0.9 * *$ & $30 \pm 2.5^{\text {**\#\# }}$ \\
\hline EF (\%) & $85.6 \pm 2.5$ & $22.9 \pm 3.4^{* *}$ & $67.2 \pm 2.0$ *\#\# \\
\hline
\end{tabular}

Abbreviations: BW, body weight; $\mathrm{CHF}$, chronic heart failure; CVP, central venous pressure; $\pm \mathrm{d} P / \mathrm{d} t$, rate of intra-ventricular pressure rise and decline; EAM, experimental autoimmune myocarditis; EF, ejection fraction; FS, fractional shortening; group N, aged-matched untreated rats; group T10, rats with heart failure treated with telmisartan $\left(10 \mathrm{mg} \mathrm{kg}^{-1}\right.$ day $\left.^{-1}\right)$; group V, rats with heart failure treated with vehicle; HR, heart rate; HW, heart weight; HW/BW, ratio of heart weight to body weight; LVDd, left ventricular dimension in diastole; LVDs, left ventricular dimension in systole; LVEDP, left ventricular end-diastolic pressure; LVP, left ventricular pressure; MBP, mean blood pressure; n, no. of rats.

Results are presented as the mean \pm s.e.

${ }^{*} P<0.05$ and ${ }^{* *} P<0.01$ vs. group $\mathrm{N} ;{ }^{\#} P<0.05$ and ${ }^{\#} P<0.01$ vs. group $\mathrm{V}$.

compared with those in group V. The hearts from group V rats showed massive fibrosis compared with those from group $\mathrm{N}$ rats (Figures $2 \mathrm{~b}$ and b1). The percentage of fibrosis was significantly lower in the telmisartan-treated rats than in vehicle-treated rats (Figures $2 \mathrm{~b}$ and b1). The myocyte size in group $\mathrm{V}$ was significantly larger than that in group $\mathrm{N}$ (Figures $2 \mathrm{c}$ and $\mathrm{cl}$ ). Telmisartan treatment significantly reduced the myocyte size compared with that in group $\mathrm{V}$ (Figures $2 \mathrm{c}$ and $\mathrm{cl}$ ). Focal accumulations of inflammatory cell infiltration were detected in the hearts of group V rats (Figure 2d). However, the proportion of cell accumulation was less in the telmisartan-treated rats (Figure $2 \mathrm{~d}$ ).

\section{Myocardial expression of PPAR- $\gamma$ by immunohistochemistry and western blot \\ Immunohistochemical analysis of rat hearts in group $\mathrm{V}$ showed enhanced expression of PPAR- $\gamma$ compared with that in normal rat hearts (Figures $2 \mathrm{a}$ and a1). Myocardial immunoreactivity for PPAR- $\gamma$ was significantly decreased in the telmisartan-treated rats compared with that in the vehicle-treated rats (Figures $2 \mathrm{a}$ and a1). Only marginal or trivial immunoreactivity for PPAR- $\gamma$ was detected in myocardium of normal rats. Treatment with telmisartan significantly decreased the myocardial level of PPAR- $\gamma$ protein compared with that in group $\mathrm{V}$ rats (Figures $1 \mathrm{c}$ and $\mathrm{d}$ ).}

\section{Myocardial mRNA expressions of collagen-I and III, TGF- $\beta 1$ and ANP}

RT-PCR analysis showed that collagen-I and III, TGF- $\beta 1$, and atrial natriuretic peptide (ANP) mRNA expression levels were significantly increased in vehicle-treated rats, compared with those in group $\mathrm{N}$ rats (Figures $3 \mathrm{a}-\mathrm{d}$ ). In contrast, treatment with telmisartan significantly decreased the myocardial mRNA expressions of collagen-I and III, TGF- $\beta 1$, and ANP compared with those in group V rats (Figures 3a-d).

\section{Myocardial mRNA expressions of inflammatory cytokines and MMPs}

RT-PCR data showed that IL-6, IL-1 $\beta$ and monocyte chemoattractant protein-1 (MCP-1) mRNA expression levels were significantly increased in vehicle-treated rats compared with those in group $\mathrm{N}$ rats (Figures $4 \mathrm{a}-\mathrm{c}$ ). In contrast, treatment with telmisartan significantly decreased the myocardial mRNA expressions of IL-6, IL-1 $\beta$ and MCP-1 compared with those in group $\mathrm{V}$ rats (Figures $4 \mathrm{a}-\mathrm{c}$ ). Moreover, mRNA expressions of matrix metalloproteinase (MMP)-2 and -9 were significantly increased in vehicle-treated rats compared with those in group $\mathrm{N}$ rats (Figures $5 \mathrm{a}$ and $\mathrm{b}$ ). However, treatment with telmisartan significantly reduced the myocardial mRNA expressions of MMP-2 and -9 compared with those in group $\mathrm{V}$ rats (Figures $5 \mathrm{a}$ and $\mathrm{b}$ ).

\section{DISCUSSION}

The results of this study show that the treatment with oral telmisartan improved both systolic $(+\mathrm{d} P / \mathrm{d} t, \%$ ejection fraction and \% FS) and diastolic $(-\mathrm{d} P / \mathrm{d} t$ and $\mathrm{LV}$ end-diastolic pressure) functions, increased neurohormonal parameters such as plasma Ang-II, and ameliorated myocardial remodeling and its marker molecules.

Myocardial fibrosis probably has an important role in both diastolic and systolic dysfunction ${ }^{18}$ and has adverse clinical consequences that result in increases in mortality because of progressive heart failure. It has been suggested that the increase in myocardial fibrosis during heart failure is due to both increased collagen synthesis by fibroblasts and unchanged or decreased fibrillar collagen degradation. ${ }^{19}$ Myocardial fibrosis, the hallmark of DCM, is observed in DCM hearts as indicated by Azan-Mallory staining and increases in the levels of its marker molecules (TGF- $\beta 1$, collagen-I and collagen-III) (Figures $2 \mathrm{~b}$ and $3 \mathrm{a}-\mathrm{c}$ ). Ang-II is known to stimulate fibrous tissue formation by promoting TGF- $\beta 1$ synthesis through $\mathrm{AT}_{1} \mathrm{R}$ and is a major determinant of cardiac remodeling. ${ }^{20}$ Ang-II also stimulates cardiac collagen production by promoting TGF- $\beta 1$ synthesis through $\mathrm{AT}_{1} \mathrm{R}$ receptor activation. ${ }^{21}$ In addition, $\mathrm{AT}_{1} \mathrm{R}$ activation has a role in the molecular changes associated with coronary matrix remodeling in diabetes. ${ }^{21}$ Furthermore, $\mathrm{AT}_{1} \mathrm{R}$ blockade reduces myocardial hypertrophy, decreases myocardial fibrosis and attenuates cardiac remodeling. ${ }^{22}$ Consistent with previous studies, ${ }^{21,22}$ we have also observed increased expressions of TGF- $\beta 1$ and collagen-III mRNA in group V, and these increased mRNA levels were suppressed by telmisartan treatment (Figures $3 \mathrm{a}-\mathrm{c}$ ). Taken together with the above reports, these findings suggest that $\mathrm{AT}_{1} \mathrm{R}$ has an important role in cardiac remodeling through expression of TGF- $\beta 1$ and collagen-III mRNA, and that telmisartan may contribute to the inhibition of cardiac remodeling. However, more evidence is needed to support this hypothesis.

The myocardial ECM is a complex network and its balance determines the structural integrity of the heart. Alteration in the matrix degradation system caused by inflammatory mediators, oxygen species, and neurohumoral reactions leads to an impairment of LV function as observed in myocarditis and inflammatory cardiomyopathy. ${ }^{23}$ The imbalance of the matrix-degrading system with induced expressions of MMPs and plasminogen activators as well as the reduced expressions of tissue inhibitors of MMPs leads to a pathologic collagen turnover, with the loss of structural integrity of the heart and an impairment of LV function. ${ }^{23}$ Interestingly, we could observe an increase in myocardial mRNA levels of MMP-2 and -9 in rats with DCM (Figure 5). It is reported that $\mathrm{AT}_{1} \mathrm{R}$ may be involved in the development of cardiac hypertrophy by increasing ECM 

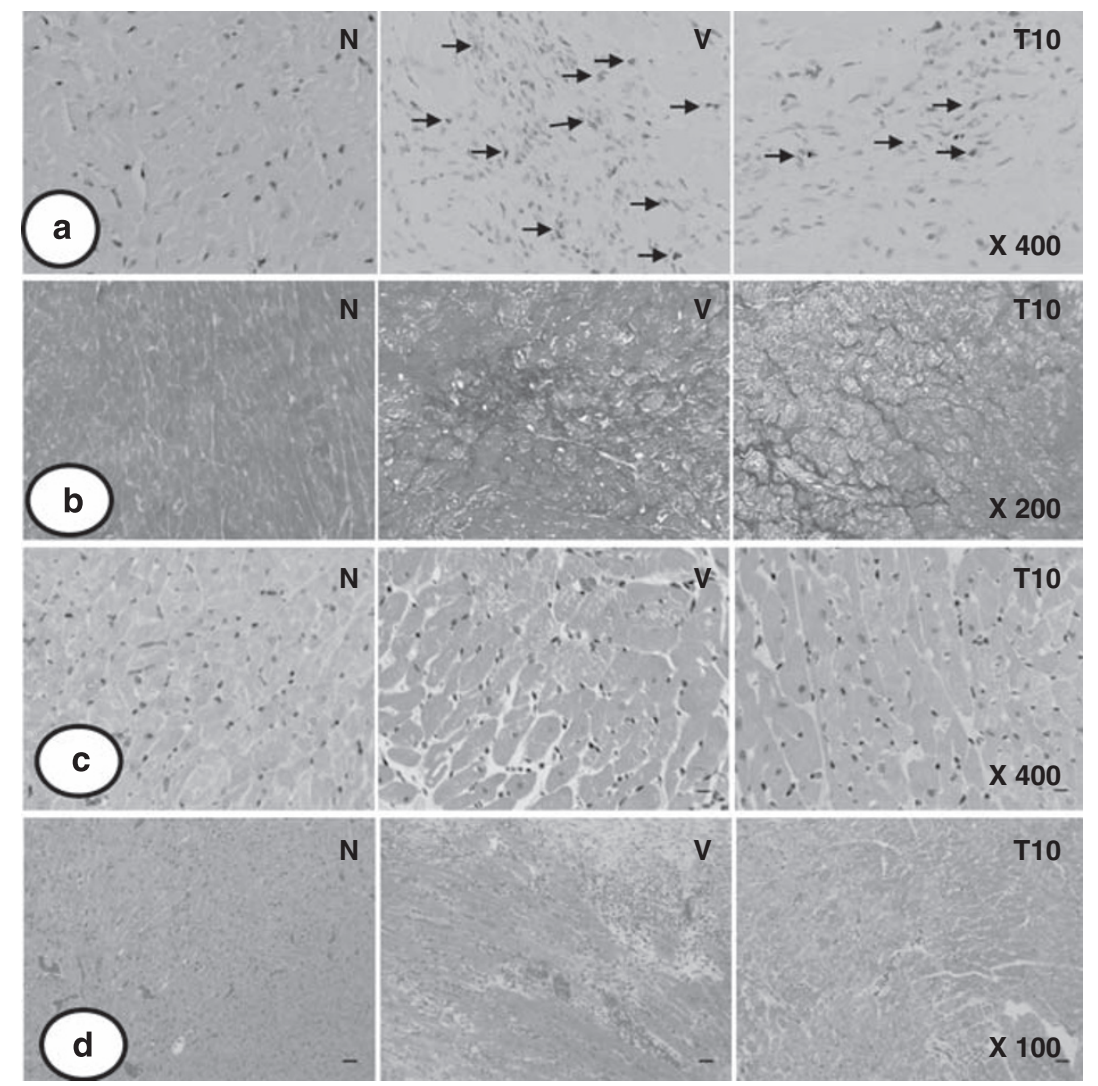
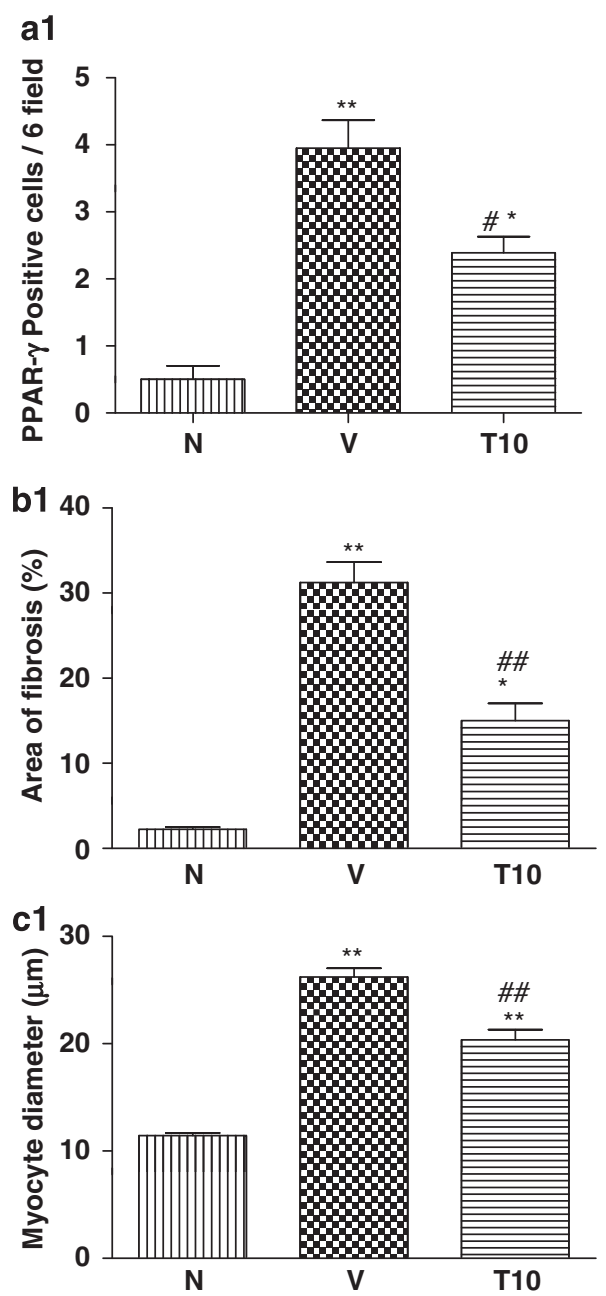

Figure 2 Effects of telmisartan on myocardial remodeling in rats with CHF induced by autoimmune myocarditis. (a) Immunohistochemistry of PPAR- $\gamma$ (counterstained with hematoxylin; $\times 400$ ). (b) Azan-Mallory staining for fibrosis of the cross-sectional tissue slices of hearts. Fibrosis is indicated by the blue area as opposed to the red myocardium $(\times 200)$. (c) Hematoxylin and eosin staining of the cross-sectional tissue slices of hearts depicting cardiomyocyte hypertrophy $(\times 400)$. (d) Extensive inflammatory cell infiltration was observed in the hearts of myosin-immunized rats (hematoxylin-eosin staining; $\times 100)$. Bar graph shows quantitative analysis of PPAR- $\gamma$-positive cells (a1), fibrosis (b1), and myocyte diameter (c1) in groups N, V and T10. Group N, age-matched untreated rats; group V, CHF rats administered with vehicle; group T10, CHF rats treated with telmisartan $\left(10 \mathrm{mg} \mathrm{kg}^{-1}\right.$ day $\left.^{-1}\right)$. The values are mean \pm s.e.m. ${ }^{*} P<0.05$ and ${ }^{* *} P<0.01$ vs. group $\mathrm{N} ;{ }^{\#} P<0.01$ vs. group V. A full color version of this figure is available at the Hypertension Research journal online.

accumulation. ${ }^{24}$ Furthermore, it is reported that in hypertensive Dahl salt-sensitive rats, local activation of Ang-II in hypertrophic LV triggers ECM degradation resulting in LV remodeling and treatment with telmisartan preserves LV shape and function, ECM density, and decreases oxidative stress-mediated protein degeneration. ${ }^{25}$ In agreement with a previous study, ${ }^{25}$ telmisartan treatment significantly decreased myocardial mRNA levels of MMP-2 and -9 , resulting in improved myocardial function, which in turn supports the notion that $\mathrm{AT}_{1}$ receptors are involved in ECM remodeling.

It has been reported that $\mathrm{AT}_{1} \mathrm{R}$ antagonists cause an increase in plasma Ang-II level, which selectively stimulates $\mathrm{AT}_{2} \mathrm{R}$, and that this stimulation inhibits cardiac fibroblast growth and ECM formation and exerts a negative chronotropic effect, indicating that $\mathrm{AT}_{2} \mathrm{R}$ stimulation has a novel cardioprotective effect. ${ }^{26}$ Interestingly, we could observe an elevated Ang-II level in the telmisartan-treated rats compared with that in the CHF rats. These results may support the hypothesis that Ang-II $\mathrm{AT}_{2} \mathrm{R}$ stimulation by $\mathrm{AT}_{1}$ blockade-induced increases in Ang-II plasma levels results in antifibrotic effects.
Plasma ANP concentration is a useful prognostic indicator in patients with CHF, and is documented to be elevated in cardiac hypertrophy or failure. ${ }^{27}$ Vehicle-treated rats had developed cardiac hypertrophy and LV dilation, as indicated by increase in mRNA levels of ANP (Figure 3d), myocyte size, HW, HW/BW, and LV diastolic and systolic dimensions, and a decrease in FS (Figure $2 \mathrm{cl}$ and Table 1). A significant reduction in these parameters and an increase in FS were observed in the telmisartan-treated rats. Taken together, these results indicate that telmisartan improved LV function and ameliorated the progression of cardiac remodeling.

Recent studies have shown that thiazolidinediones, PPAR- $\gamma$ agonists, attenuate autoimmune myocarditis, ${ }^{28,29}$ cardiac hypertrophy ${ }^{30}$ and myocardial ischemia-reperfusion injury, ${ }^{31}$ through the inhibition of infiltration of inflammatory cells or upregulation of cytokines in myocardium, which indicates that PPAR- $\gamma$ agonist activity may have anti-inflammatory effects in myocardium. Mechanistically, PPAR- $\gamma$ ligands act at least in part by inhibiting the activity of transcription factors such as activator protein-1, signal transducers and activators of 

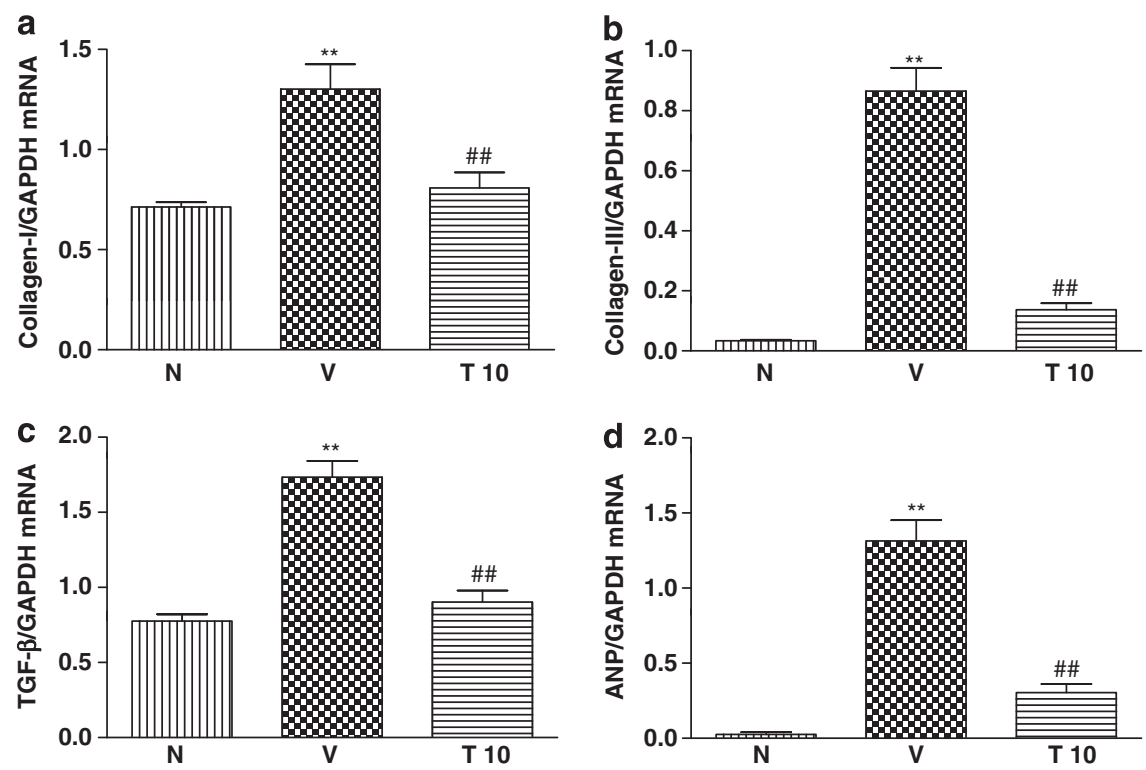

Figure 3 Myocardial messenger RNA expression levels of collagen-I (a), collagen-III (b), TGF- $\beta 1$ (c) and ANP (d) in rats with CHF were determined by quantitative RT-PCR. The expression level of each sample was expressed relative to the expression level of GAPDH gene. Data are mean \pm s.e.m. of five-seven rats. Group N, age-matched untreated rats; group V, CHF rats administered with vehicle; group T10, $\mathrm{CHF}_{\text {rats }}$ treated with telmisartan $\left(10 \mathrm{mg} \mathrm{kg}^{-1} \mathrm{day}^{-1}\right)$. The values are mean \pm s.e.m. ${ }^{*} P<0.01$ vs. group $\mathrm{N} ;{ }^{\#} P<0.01$ vs. group $\mathrm{V}$.
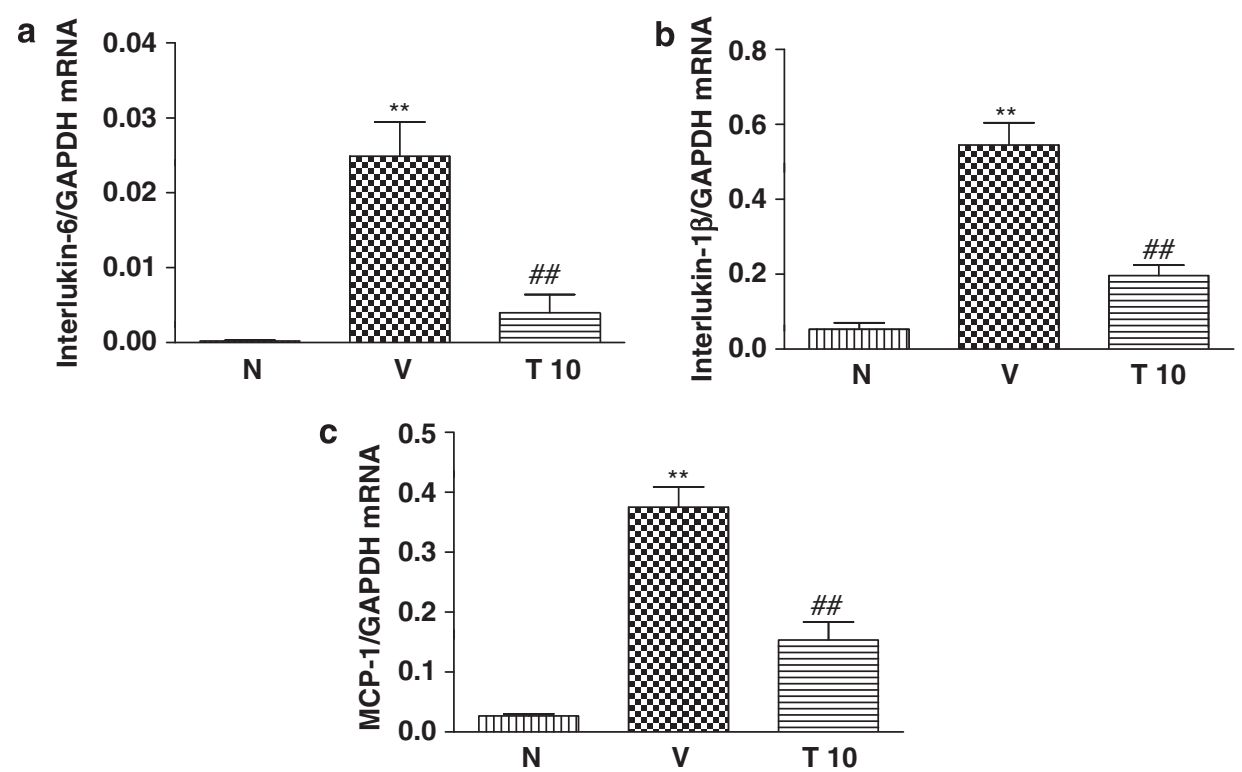

Figure 4 Myocardial messenger RNA expression levels of IL-6 (a), IL-1 $\beta$ (b) and MCP-1 (c) in rats with CHF were determined by quantitative RT-PCR. The expression level of each sample was expressed relative to the expression level of glyceraldehyde-3-phosphate dehydrogenase (GAPDH) gene. Data are mean \pm s.e.m. of five-seven rats. Group N, age-matched untreated rats; group V, CHF rats administered with vehicle; group T10, CHF rats treated with telmisartan $\left(10 \mathrm{mg} \mathrm{kg}^{-1} \mathrm{day}^{-1}\right)$. The values are mean \pm s.e.m. ${ }^{* *} P<0.01$ vs. group $\mathrm{N}$; ${ }^{\# \#} P<0.01$ vs. group $\mathrm{V}$.

transcription-1 and nuclear factor-kB. ${ }^{32}$ In addition, activation of PPAR- $\gamma$ has been reported to decrease expression of $\mathrm{AT}_{1} \mathrm{R}$ and inhibit the effects of Ang-II on intracellular pathways. ${ }^{33}$ Recently, it has been reported that telmisartan ameliorated cardiac remodeling in DSsensitive hypertensive rats through PPAR- $\gamma$-endothelial nitric oxide synthase pathway. ${ }^{34}$ Although Takano et al. ${ }^{35}$ reported that PPAR- $\gamma$ was expressed in neonatal normal cardiac myocytes, in this study, immunohistochemical results have shown that only marginal or trivial immunoreactivity for PPAR- $\gamma$ was detected in myocardium of normal rats. Interestingly, we also observed increased expression of PPAR- $\gamma$ in rats with DCM in line with the previous reports ${ }^{29,36,37}$ and these changes were significantly decreased by telmisartan treatment (Figures $1 \mathrm{c}, \mathrm{d}, 2 \mathrm{a}$ and a1). The reason behind reduced PPAR- $\gamma$ expression in rats treated with telmisartan remains to be determined. In addition, because we only measured the expression of PPAR- $\gamma$ and did not measure the activity of PPAR- $\gamma$, the net effect of telmisartan on overall 

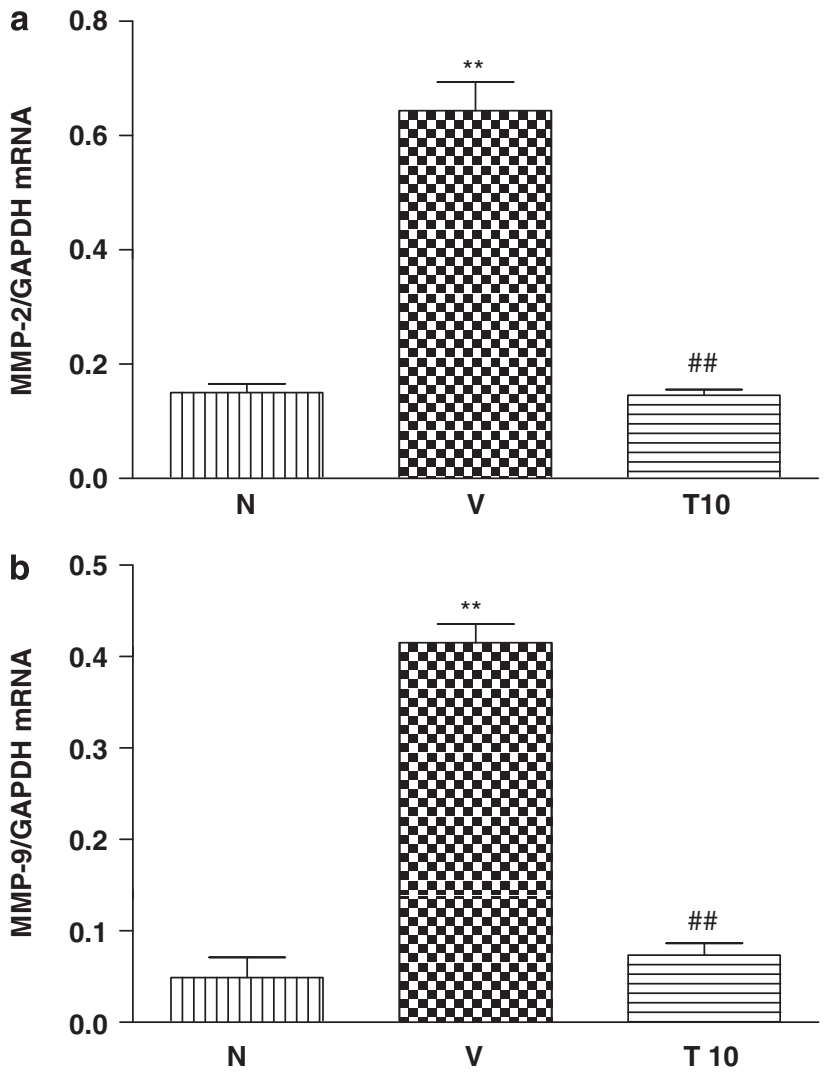

Figure 5 Myocardial messenger RNA expression levels of MMP-2 (a) and MMP-9 (b) in rats with CHF were determined by quantitative RT-PCR. The expression level of each sample was expressed relative to the expression level of glyceraldehyde-3-phosphate dehydrogenase (GAPDH) gene. Data are mean \pm s.e.m. of five-seven rats. Group N, age-matched untreated rats; group V, CHF rats administered with vehicle; group T10, CHF rats treated with telmisartan $\left(10 \mathrm{mg} \mathrm{kg}^{-1}\right.$ day $\left.^{-1}\right)$. The values are mean \pm s.e.m. ${ }^{* *} P<0.01$ vs. group $\mathrm{N}$; ${ }^{\# \#} P<0.01$ vs. group $\mathrm{V}$.

PPAR- $\gamma$ activity in our model is unclear. In light of this study limitation, further experiments will be required to understand whether the effects of telmisartan in our model are mediated by alterations in PPAR- $\gamma$ activity.

Several clinical studies have described the participation of proinflammatory cytokines in the pathogenesis of cardiac diseases. The levels of circulating proinflammatory cytokines such as tumor necrosis factor- $\alpha$ and IL- 1 and IL- 6 are elevated in patients with myocarditis. ${ }^{38}$ In a murine model of viral myocarditis, the intracardiac expression of tumor necrosis factor- $\alpha$, IL- $1 \beta$, interferon- $\gamma$ and IL-2 genes were increased. ${ }^{39}$ It has been shown that MCP-1 a member of the C-C chemokine family may have an important role in the pathogenesis of human acute myocarditis as well as in the progression of rat EAM. ${ }^{40}$ The degree of expression was correlated with the severity of the disease, which suggests that the overproduction of proinflammatory cytokines and chemokines may aggravate the disease. This is supported in part by recent reports that the overexpression of tumor necrosis factor- $\alpha$ in heart caused severe myocarditis and cardiomyopathy in transgenic mice, ${ }^{41}$ and that IL- $1 \beta$ as well as tumor necrosis factor- $\alpha$ promoted the aggravation of viral myocarditis in virus-resistant mice. ${ }^{42}$ It has been reported that Ang-II induces inflammation through the production of reactive oxygen species, adhesion molecules and inflammatory cytokines such as MCP- $1 .{ }^{43}$
$\mathrm{AT}_{1}$ antagonists are reported to suppress cytokine production and transcription of cytokine genes in vitro and in vivo, ${ }^{8,9,44}$ and significantly decrease MCP- 1 expression. ${ }^{45}$ Interestingly, we could observe an increase in the myocardial mRNA levels of IL-6, IL- $1 \beta$ and MCP- 1 and inflammatory cell infiltration in rats with DCM, and these changes in mRNA levels were significantly decreased by telmisartan treatment (Figures 4 and 2d).

These results suggest that the beneficial effects of telmisartan in EAM may be partly due to the suppression of inflammatory events in the myocardium. Furthermore, telmisartan treatment might be a promising new therapy for chronic myocarditis, particularly for LV remodeling in which ongoing autoimmune processes may have a role in disease development. Moreover, we show for the first time that telmisartan suppressed cytotoxic myocardial damage in heart failure after EAM.

In conclusion, this study indicates that telmisartan provides remarkable chronic cardioprotection, reducing or eliminating cardiac remodeling in a model of DCM, and may help us to identify why this drug is efficacious at significantly improving outcome and survival when used for the treatment of heart failure in humans.

\section{ACKNOWLEDGEMENTS}

This research was supported by a Yujin Memorial Grant, Ministry of Education, Culture, Sports, Science and Technology, Japan and by a grant from the Promotion and Mutual Aid Corporation for Private Schools, Japan. We thank Wawaimuli Arozal, Flori Ratna Sari, Hiroko Shimazaki, Sayaka Egawa, Fuji Tomohiko, Kana Kawadura, Yoshiyasu Kobayashi, Yuhki for their assistance in this research work. We also express our sincere gratitude to Dr Masaki Nagata (Division of Oral and Maxillofacial Surgery, Niigata University Graduate School of Medical and Dental Sciences, Niigata, Japan) for carrying out the RT-PCR analysis in this study.

1 Taliercio CP, Seward JB, Driscoll DJ, Fisher LD, Gersh BJ, Tajik AJ. Idiopathic dilated cardiomyopathy in the young: clinical profile and natural history. J Am Coll Cardiol 1985; 6: 1126-1131.

2 Dec GW, Palacios IF, Fallon JT, Aretz HT, Mills J, Lee DC, Johnson RA. Acute myocarditis in the spectrum of acute dilated cardiomyopathies. Clinical features, histologic correlates, and clinical outcome. N Engl J Med 1985; 312: 885-890.

3 Klingel K, Hohenadl C, Canu A, Albrecht M, Seemann M, Mall G, Kandolf R. Ongoing enterovirus-induced myocarditis is associated with persistent heart muscle infection: quantitative analysis of virus replication, tissue damage, and inflammation. Proc Natl Acad Sci USA 1992; 89: 314-318.

4 Cohn JN, Tognoni G. A randomized trial of the angiotensin receptor blocker valsartan in chronic heart failure. N Engl J Med 2001; 345: 1667-1675.

5 Yuan Z, Nimata M, Okabe TA, Shioji K, Hasegawa K, Kita T, Kishimoto C. Olmesartan, a novel $\mathrm{AT}_{1}$ antagonist, suppresses cytotoxic myocardial injury in autoimmune heart failure. Am J Physiol Heart Circ Physiol 2005; 289: H1147-H1152.

6 Swynghedauw B. Molecular mechanisms of myocardial remodeling. Physiol Rev 1999; 79: 215-262.

7 Schelling P, Fischer H, Ganten D. Angiotensin and cell growth: a link to cardiovascular hypertrophy? J Hypertens 1991; 9: 3-15.

8 Mollnau H, Wendt M, Szocs K, Lasseque B, Schulz E, Oelze M, Li H, Bodenschatz M, August M, Kleschyov AL, Tsilimingas N, Walter U, Förstermann U, Meinertz T, Griendling K, Münzel T. Effects of angiotensin II infusion on the expression and function of $\mathrm{NAD}(\mathrm{P}) \mathrm{H}$ oxidase and components of nitric oxide/cGMP signaling. Circ Res 2002; 90: E58-E65.

9 Burnier M. Angiotensin II type 1 receptor blockers. Circulation 2001; 103: 904-912.

10 Nimata M, Kishimoto C, Yuan Z, Shioji K. Beneficial effects of olmesartan, a novel angiotensin II receptor type 1 antagonist, upon acute autoimmune myocarditis. $\mathrm{Mol}$ Cell Biochem 2004; 259: 217-222.

11 Shirai K, Watanabe K, Ma M, Wahed M, Inoue M, Saito Y, Suresh PS, Kashimura T, Tachikawa H, Kodama M, Aizawa Y. Effects of angiotensin-II receptor blockers candesartan cilexetil in rats with dilated cardiomyopathy. Mol Cell Biochem 2005; 269: 137-142.

12 Cooper Jr LT. Pathology of human myocarditis. In Cooper Jr LT (ed), Myocarditis—from Bench to Bedside. Humana Press: New Jersey, 2003, pp 358-359.

13 Kodama M, Hanawa H, Saeki M, Hosono H, Inomata T, Suzuki K, Shibata A. Rat dilated cardiomyopathy after autoimmune giant cell myocarditis. Circ Res 1994; 75: 278-284. 
14 Watanabe K, Ohta Y, Nakazawa M, Higuchi H, Hasegawa G, Naito M, Fuse K, Ito M, Hirono S, Tanabe N, Hanawa H, Kato K, Kodama M, Aizawa Y. Low dose carvedilol inhibits progression of heart failure in rats with dilated cardiomyopathy. Br J Pharmacol 2000; 130: 1489-1495.

15 Kodama M, Matsumoto Y, Fujiwara M, Masani F, Izumi T, Shibata A. A novel experimental model of giant cell myocarditis induced in rats by immunization with cardiac myosin fraction. Clin Immunol Immunopathol 1990; 57: 250-262.

16 Liang B, Leenen FH. Prevention salt induced hypertension and fibrosis by $\mathrm{AT}_{1}$-receptor in Dahl S rats. J Cardiovasc Pharmacol 2008; 51: 457-466.

17 Yamaguchi K. Effects of water deprivation on immunoreactive angiotensin II levels in plasma, cerebroventricular perfusate and hypothalamus of the rat. Acta Endocrinol (Copenh) 1981; 97: 137-144.

18 Weber KT, Brilla CG, Janicki JS. Myocardial fibrosis: functional significance and regulatory factors. Cardiovasc Res 1993; 27: 341-348.

19 Weber KT, Eghbali M. Collagen matrix synthesis and degradation in the development and regression of left ventricular hypertrophy. Cardiovasc Rev Rep 1991; 12: 61-69.

20 Sun Y, Zhang JQ, Zhang J, Ramires FJ. Angiotensin II, transforming growth factor-beta1 and repair in the infarcted heart. J Mol Cell Cardiol 1998; 30: 1559-1569.

21 Jesmin S, Sakuma I, Hattori Y, Kitabatake A. Role of angiotensin II in altered expression of molecules responsible for coronary matrix remodeling in insulin-resistant diabetic rats. Arterioscler Thromb Vasc Biol 2003; 23: 2021-2026.

22 Smits JF, van Krimpen C, Schoemaker RG, Cleutjens JP, Daemen MJ. Angiotensin-II receptor blockade after myocardial infarction in rats: effects on hemodynamics, myocardial DNA synthesis, and interstitial collagen content. J Cardiovasc Pharmacol 1992; 20: 772-778.

23 Rutschow S, Li J, Schultheiss HP, Pauschinger M. Myocardial proteases and matrix remodeling in inflammatory heart disease. Cardiovasc Res 2006; 69: 646-656.

24 Brilla CG, Zhou G, Rupp H, Maisch B, Weber KT. Role of angiotensin II and prostaglandin $E_{2}$ in regulating cardiac fibroblast collagen turnover. Am J Cardiol 1995; 76: 80-130.

25 Takenaka H, Kihara Y, Iwanaga Y, Onozawa Y, Toyokuni S, Kita T. Angiotensin II, oxidative stress, and extracellular matrix degradation during transition to LV failure in rats with hypertension. J Mol Cell Cardiol 2006; 41: 989-997.

26 Matsubara H. Pathophysiological role of angiotensin II type 2 receptor in cardiovascular and renal diseases. Circ Res 1998; 83: 1182-1191.

27 Falcao LM, Pinto F, Ravara L, van Zwieten PA. BNP and ANP as diagnostic and predictive markers in heart failure with left ventricular systolic dysfunction. J ReninAngiotensin-Aldosterone Syst 2004; 5: 121-129.

28 Yuan Z, Liu Y, Liu Y, Zhang J, Kishimoto C, Wang Y, Ma A, Liu Z. Peroxisome proliferation-activated receptor-gamma ligands ameliorate experimental autoimmune myocarditis. Cardiovasc Res 2003; 59: 685-694.

29 Yuan Z, Liu Y, Liu Y, Zhang J, Kishimoto C, Wang Y, Ma A, Liu Z. Cardioprotective effects of peroxisome proliferator activated receptor gamma activators on acute myocarditis: anti-inflammatory actions associated with nuclear factor kappaB blockade. Heart 2005; 91: 1203-1208.

30 Sakai S, Miyauchi T, Irukayama-Tomobe Y, Ogata T, Goto K, Yamaguchi I. Peroxisome proliferator-activated receptor-gamma activators inhibit endothelin-1-related cardiac hypertrophy in rats. Clin Sci 2002; 103: 16S-20S.
31 Ito $\mathrm{H}$, Nakano A, Kinoshita M, Matsumori A. Pioglitazone, a peroxisome proliferatoractivated receptor-gamma agonist, attenuates myocardial ischemia/reperfusion injury in a rat model. Lab Invest 2003; 83: 1715-1721.

32 Khandoudi N, Delerive P, Berrebi-Bertrand I, Buckingham RE, Staels B, Bril A. Rosiglitazone, a peroxisome proliferator-activated receptor-gamma, inhibits the Jun $\mathrm{NH}(2)$-terminal kinase/activating protein 1 pathway and protects the heart from ischemia/reperfusion injury. Diabetes 2002; 51: 1507-1514.

33 Takeda K, Ichiki T, Tokunou T, Funakoshi Y, lino N, Hirano K, Kanaide H, Takeshita A. Peroxisome proliferator-activated receptor gamma activators downregulate angiotensin II type 1 receptor in vascular smooth muscle cells. Circulation 2000; 102: 1834-1839.

34 Kobayashi N, Ohno T, Yoshida K, Fukushima H, Mamada Y, Nomura M, Hirata H, Machida Y, Shinoda M, Suzuki N, Matsuoka H. Cardioprotective mechanism of telmisartan via PPAR-gamma-eNOS pathway in dahl salt-sensitive hypertensive rats. Am J Hypertens 2008; 21: 576-581.

35 Takano H, Nagai T, Asakawa M, Toyozaki T, Oka T, Komuro I, Saito T, Masuda Y. Peroxisome proliferator-activated receptor activators inhibit lipopolysaccharideinduced tumor necrosis factor-alpha expression in neonatal rat cardiac myocytes. Circ Res 2000; 87: 596-602.

36 Son NH, Park TS, Yamashita H, Yokoyama M, Huggins LA, Okajima K, Homma S, Szabolcs MJ, Huang LS, Goldberg IJ. Cardiomyocyte expression of PPARgamma leads to cardiac dysfunction in mice. J Clin Invest 2007; 117: 2791-2801.

37 Yuan ZY, Liu Y, Liu Y, Zhang JJ, Kishimoto C, Wang YN, Ma AQ, Liu ZQ. PPAR-gamma ligands inhibit the expression of inflammatory cytokines and attenuate autoimmune myocarditis. Chin Med J 2004; 117: 1253-1255.

38 Matsumori A, Yamada T, Suzuki H, Matoba Y, Sasayama S. Increased circulating cytokines in patients with myocarditis and cardiomyopathy. Br Heart J 1994; 72: 561-566.

39 Nakamura H, Yamamura T, Umemoto S, Fukuta S, Shioi T, Matsumori A, Sasayama S, Matsuzaki M. Autoimmune response in chronic ongoing myocarditis demonstrated by heterotopic cardiac transplantation in mice. Circulation 1996; 94: 3348-3354.

40 Fuse K, Kodama M, Hanawa H, Okura Y, Ito M, Shiono T, Maruyama S, Hirono S, Kato $\mathrm{K}$, Watanabe K, Aizawa Y. Enhanced expression and production of monocyte chemoattractant protein-1 in myocarditis. Clin Exp Immunol 2001; 124: 346-352.

41 Kubota T, McTiernan CF, Frye CS, Demetris AJ, Feldman AM. Cardiac-specific overexpression of tumor necrosis factor-alpha causes lethal myocarditis in transgenic mice. J Card Fail 1997; 3: 117-124.

42 Kishimoto C, Takada H, Kawamata H, Umatake M, Ochiai H. Immunoglobulin treatment prevents congestive heart failure in murine encephalomyocarditis viral myocarditis associated with reduction of inflammatory cytokines. J Pharmacol Exp Ther 2001; 299: 645-651.

43 Willemsen JM, Westerink JW, Dallinga-Thie GM, Van Zonneveld AJ, Gaillard CA, Rabelink TJ, de Koning EJ. Angiotensin-II type 1 receptor blockade improves hyperglycemia-induced endothelial dysfunction and reduces proinflammatory cytokine release from leukocytes. J Cardiovasc Pharmacol 2007; 49: 6-12.

44 Kramer C, Sunkomat J, Witte J, Luchtefeld M, Walden M, Schmidt B. Angiotensin II receptor-independent anti-inflammatory and anti-aggregatory properties of losartan: role of the active metabolite EXP 3179. Circ Res 2002; 90: 770-776.

45 Dai Q, Xu M, Yao M, Sun B. Angiotensin $A_{T 1}$ receptor antagonists exert anti-inflammatory effects in spontaneously hypertensive rats. Br J Pharmacol 2007; 152: 1042-1048. 